\title{
A extensão universitária sob foco de estudo: reflexões sobre limites e desafios
}

\author{
The university community project as the focus of study: reflections on limits and \\ challenges
}

\author{
Egeslaine de Nez ${ }^{1}$, Fernanda Esser ${ }^{2}$ \\ 1 Professora. Universidade do Estado de Mato Grosso (UNEMAT), Brasil. E-mail: egeslaine@unemat.br ou e.denez@yahoo.com.br \\ 2 Licenciada. Universidade do Estado de Mato Grosso (UNEMAT), Brasil. E-mail: fernandaesser@yahoo.com.br
}

Recebido em: 10/03/2015 | Aprovado em: 11/09/2015

DOI: 10.12957/interag.2016.15543

\section{Resumo}

Este artigo objetiva analisar as práticas extensionistas desenvolvidas na Universidade do Estado de Mato Grosso (Unemat), especificamente no Campus Universitário Vale do Teles Pires (Colider/MT). Sua relevância é a possibilidade de socializar as limitações e os desafios dessas ações. Os procedimentos metodológicos deste estudo foram: pesquisa bibliográfica, documental e de campo (questionário) com abordagem analítica qualitativa. Analisar a extensão universitária foi uma tarefa árdua e complexa, sendo necessário entendê-la como um mecanismo de aproximação com a sociedade. Os resultados fundamentaram a percepção de que a extensão é uma das funções universitárias que juntamente com o ensino e a pesquisa, possibilita que as instituições cumpram sua responsabilidade que se refere ao desenvolvimento econômico e social. E para que isto se torne possível, é preciso que socializem na comunidade os conhecimentos que produzem nas pesquisas, isso acontece por meio dos projetos extensionistas. Enfim, constatou-se que a universidade que desempenha o tripé constitucional (ensino, pesquisa e extensão) consegue assimilar as demandas sociais $e$ incorporá-las em suas ações.

Palavras-chave: Universidade. Extensão. Sociedade.

Área temática: Educação. Linha de extensão: Educação.

\begin{abstract}
The university community project as the focus of study: reflections on limits and challenges

Abstract: This article aims at analyzing the community projects developed at the State University of Mato Grosso (Unemat), specifically in Campus Vale do Teles Pires (Colider/MT). Its relevance resides in the possibility of sharing the limitations and challenges of these actions. The methodological procedures of this study were: documentary, bibliography and field research (questionnaire), qualitative, analytical approach. The analysis of the university community project was a hard and complex task, since it was necessary to understand it as a mechanism of approximation with society. The results founded the perception that the community project is a university function that, together with teaching and researching, enables institutions to fulfill their responsibility in economic and social development. In order to accomplish this, it is necessary to introduce the knowledge produced by research in society, which is achieved through the community projects. Finally, it is clear that the university that plays the constitutional tripod (teaching, research and community work) can assimilate social demands and incorporate them in their actions.
\end{abstract}

Keywords: University. Community work. Society.

\section{Introdução}

As universidades possuem hoje uma tripla função; todavia, o ensino foi sua finalidade precípua, passando, posteriormente para a pesquisa e, somente nos últimos tempos, foi- 
lhe acrescida a função extensionista. É nessa atividade que estão concentrados os esforços para quebrar os "muros" institucionais e torná-la pública e democrática. Isso é de fundamental importância para a própria instituição, para a comunidade e para o meio acadêmico que tem grande oportunidade de ampliar seus conhecimentos.

É notório que desde seu surgimento atua de forma ampla, de acordo com desafios que lhes foram apresentados. ${ }^{1}$ Porém, é preciso relembrar que não pode se restringir apenas a socialização do conhecimento, estando também correlacionada aos objetivos econômicos, políticos, sociais e culturais de uma região que atende. Neste sentido, o ensino, a pesquisa e a extensão são as funções básicas de uma Universidade comprometida com a formação integral do indivíduo e sua inserção na comunidade.

"Esses três papéis centrais devem ser equivalentes e praticados no mesmo patamar de importância para que não seja violado o preceito constitucional”. ${ }^{2}$ Isto porque o artigo 207 da Constituição Federal enfatiza que "as universidades gozam de autonomia didático-científica, administrativa e de gestão financeira e patrimonial e obedecerão ao princípio da indissociabilidade entre ensino, pesquisa e extensão". ${ }^{3}$

Com esse princípio, as universidades podem transformar o ambiente no qual estão inseridas, e quanto mais estiver envolvida com esse pressuposto, mais próxima estará da realidade, promovendo o desenvolvimento do país bem como das pessoas que nele vivem. Surge, então, a particularidade deste estudo, a extensão universitária, que é conceituada como:

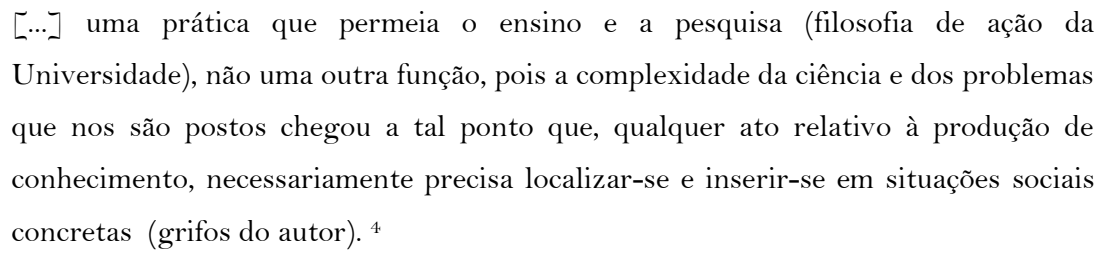

As atividades extensionistas surgiram da necessidade de se criar um elo entre universidade e sociedade, sendo caracterizada como uma importante função que, relacionando o ensino e a pesquisa socializa o conhecimento produzido, salientando sua responsabilidade social. A extensão é um processo cultural, educativo e científico que associa o ensino e a pesquisa e viabiliza a relação transformadora entre universidade e sociedade. $^{5}$ 
Essas ações são imprescindíveis, pois são fontes de aprendizado que possibilitam a geração de novos conhecimentos que contribuem para a formação cidadã e profissional do acadêmico, oportunizando o trabalho a partir da realidade, cooperando para a construção de uma sociedade justa e democrática.

\section{Notas históricas sobre as universidades}

A universidade tem como função primordial preservar e renovar a cultura nacional e universal. Assim, de acordo com o contexto em que se situa, pode ser conservadora ou transformadora. Isso significa dizer que além de formar pessoas aptas para o mercado de trabalho, também têm papel no desenvolvimento de cidadãos. Desempenham igualmente papel fundamental nas tarefas da pesquisa e da extensão.

\footnotetext{
Muitos veem a universidade como o lugar historicamente apropriado para a criação e divulgação do saber, para o desenvolvimento da ciência, para a formação de profissionais e intelectuais. Outros a percebem como uma instituição social que articula o ensino, a pesquisa e a extensão nos níveis mais elevados da política educacional de um país, satisfazendo os requisitos da sociedade. ${ }^{6}$
}

As instituições que ofertam Educação Superior originaram-se das instituições medievais, organismos criados para suprir as deficiências das escolas monásticas, que só preparavam os alunos para a carreira religiosa. Bolonha e Paris foram as primeiras universidades na Europa. A primeira, mais antiga, e a segunda, uma das mais importantes, ambas serviram de modelos para outras instituições. ${ }^{7}$

A partir do século XIII, as universidades começaram a se expandir fora dos territórios da França e Itália, nascendo a Universidade de Lisboa (1290), fato relevante para o Brasil. ${ }^{8}$ As instituições espalharam-se rapidamente por toda a Europa e posteriormente pelo mundo. Desde essa época, cultivou e transmitiu o conhecimento acumulado, desempenhando um acentuado papel social.

No início do século XVI, o sistema universitário espanhol foi trazido para a América Latina, com a criação de Universidades no México, Guatemala, Peru, Cuba, Chile, Argentina entre outros países.

[...] enquanto os demais países da América criavam suas universidades já nas primeiras décadas depois do descobrimento, no Brasil o ensino superior era relegado 
aos poucos filhos de ricos que podiam estudar na Europa. O número de jovens com condições de entrar no ensino superior não era menor aqui do que nos demais países, mas a metrópole portuguesa proibiu a criação de universidades no Brasil, e mesmo depois da independência, nossa elite dirigente ainda esperou cem anos para criar a primeira universidade. ${ }^{9}$

O modelo europeu universitário francês que exercia forte influência em Portugal e Espanha foi adotado pela América Latina. Assim, a Educação Superior era destinada somente para a elite, como passaporte aos postos políticos e burocráticos. Rossato ${ }^{1}$ indica que, nesse período, quase todos os países latino-americanos já possuíam uma ou mais universidades, com exceção do Brasil.

A primeira Instituição de Educação Superior (IES) brasileira que assumiu o status de universidade foi a Universidade do Rio de Janeiro (URJ), criada em 1920, por iniciativa da Coroa Portuguesa. Em 1928, surgiu a Escola de Engenharia de Porto Alegre e, posteriormente, outras foram surgindo.

\footnotetext{
[…] a universidade brasileira, desde os seus primórdios, nos anos vinte, lutou incessantemente para ampliar sua relevância pública e construir sua identidade. Não se pode negar que, nessa luta, se apoiou em modelos estrangeiros, e nem poderia ter sido muito diferente, pois a universidade no Brasil comparando com os outros países da América Latina e da Europa surgiu muito tarde. Registrou um atraso de dois séculos, sendo um dos últimos a constituir e reconhecer oficialmente as universidades. ${ }^{6}$
}

Nos países em desenvolvimento, as universidades apresentaram notável expansão, deixaram de pertencer a uma pequena parcela da população, constituindo-se numa possibilidade de transformação do quadro socioeconômico e passaram a estar no centro das preocupações políticas. Porém, no Brasil, somente a partir da década de 30, no Governo Vargas, houve uma significativa expansão na Educação Superior. Nos anos decorrentes ocorreu grande avanço no que diz respeito à criação de novas instituições: "Essa marcha foi constante e crescente, mas a partir de 1945 acelera-se, vindo após 1960 a dar um verdadeiro salto". ${ }^{10}$

A década de 70 foi marcada pela transformação das universidades brasileiras, passando a ter como propósito principal a garantia da inserção profissional dos acadêmicos no mercado de trabalho. Já no final de 1980 ocorreu uma rápida proliferação de 
instituições particulares. Depois dessa efervescência, as instituições de Educação Superior de modo geral estagnaram-se e, somente nos anos 90, após um longo período de turbulência de ordem financeira, deu mostras de que estava recuperando sua capacidade de crescimento. ${ }^{11}$

Enfim, historicamente, depois de novecentos anos, a universidade atinge um grau de reconhecimento inquestionável e está implantada em quase todos os países do mundo. "O século XX destacou a universalização e a consolidação da diversidade de instituições". E ainda, "os tempos contemporâneos transformaram em instituições diferenciadas, dotadas de funções, objetivos e recursos bem definidos e modelos com lógicas de funcionamento localizadas”. Assim, espera-se que as Universidades cumpram o seu compromisso social se preparando e incorporando os desafios da sociedade. ${ }^{1}$

\section{Metodologia}

Esta investigação objetivou compreender as contribuições e consequências das práticas extensionistas desenvolvidas na Unemat/Campus Vale do Teles Pires (Colider/MT). Foram analisadas as limitações dessas ações e desvelaram-se os desafios a serem enfrentados.

$\mathrm{O}$ procedimento metodológico partiu de uma pesquisa bibliográfica ${ }^{12}$ e utilizou-se também da pesquisa documental. ${ }^{13}$ Posteriormente, foi realizada pesquisa de campo através de questionário ${ }^{14}$ com os coordenadores dos projetos de extensão. Após a coleta de dados, foi o momento da reflexão analítica que se baseou na abordagem qualitativa ${ }^{15}$ e fundamentou um estudo de caso. ${ }^{16,17}$

\section{Resultados e discussões}

A IES em foco nesse estudo é a Unemat que se situa no Mato Grosso, terceiro maior Estado em extensão territorial, representando $10,61 \%$ do território nacional. ${ }^{18}$ É o único a possuir características de três biomas: pantanal, cerrado e amazônia e está na região centro-oeste do país, tendo como limites: Amazonas e Pará (Norte), Tocantins e Goiás (Leste), Rondônia e Bolívia (Oeste) e Mato Grosso do Sul (Sul). ${ }^{19}$ 
Para atender a gigantesca distância territorial de Mato Grosso se transformou numa instituição com estrutura multicampi, com sede em Cáceres e com campi em diferentes regiões do Estado. Atualmente, possui treze campi, dez núcleos pedagógicos e dezoito pólos de Ensino a Distância. Os campi estão distribuídos nas cidades de: Alta Floresta, Alto Araguaia, Barra do Bugre, Cáceres, Colíder, Diamantino, Juara, Luciara, Nova Mutum, Nova Xavantina, Pontes e Lacerda, Sinop, Tangará da Serra. ${ }^{20}$

A IES existe há trinta e seis anos como instituição, mas apenas vinte sendo caracterizada enquanto universidade, e neste período representou para Mato Grosso um conjunto de experiências didáticas, científicas, pedagógicas e administrativas que a alavancou como detentora de recursos relevantes ao desenvolvimento do ensino, da pesquisa e da extensão. Deste modo, exerce função primordial no Estado, capaz de fortalecer a população regional proporcionando melhorias na condição de vida. ${ }^{21}$

Seu lema "do interior para o interior" evidencia sua missão institucional que é oferecer Educação Superior ao interior, por intermédio dos cursos de graduação e diversos programas oferecidos pelos inúmeros campi distribuídos em diferentes municípios. ${ }^{21}$ Foi com base nesse slogan que a IES consolidou-se, levando a oportunidade de formação profissional e tem conseguido atender várias regiões, dentre elas o norte do Estado no município de Colider, que é o foco desta investigação.

Essa unidade acadêmica é denominada de "Campus Universitário Vale do Teles Pires" e está localizado às margens da MT 320, a $650 \mathrm{~km}$ da capital do Estado (Cuiabá). Deu início as suas atividades em 1994 e, atualmente, dispõe de dois cursos regulares na área de Licenciatura, sendo eles: Computação (em funcionamento desde 2004) e Geografia (criado em 2013). Estes cursos são ofertados no período noturno e atendem acadêmicos das cidades circunvizinhas tais como: Terra Nova do Norte, Nova Canaã do Norte, Nova Santa Helena, Peixoto de Azevedo, Matupá, Itaúba, Guarantã do Norte, entre outras. ${ }^{20}$

Para que fosse possível realizar o levantamento dos projetos de extensão desse campus, em um primeiro momento foram buscadas as informações disponíveis no site da IES através do link: http://www.colider.unemat.br/site/?link=extensao. A partir dessa coleta preliminar foi construído o quadro 01 que norteou a pesquisa de campo. 
Vale ressaltar que no momento desse levantamento inicial, a categorização dos projetos encerrados e em andamento era a constante no quadro 01, porém como foi observado posteriormente nos questionários, hoje todos os projetos estão encerrados. Além disso, a quantidade de atividades extensionistas variou, pois não estavam indicados dois projetos, que eram: Compostagem - um terreno fértil para a consciência ambiental, e Desenvolvimento colaborativo entre universidade e escola de um sistema de automação residencial e predial. Assim, totalizou-se a existência de doze projetos.

Com base nestas informações coletadas, foram realizados questionários com nove coordenadores ( $75 \%$ da amostra). O questionário ${ }^{22}$ era composto por quatorze questões relacionadas à temática em foco, além do perfil dos respondentes (sexo, idade e formação acadêmica).

Constatou-se na análise dos dados que $67 \%$ dos coordenadores de projetos eram do sexo masculino e $33 \%$ feminino. A idade variou entre 29 e 41 anos, sendo que $11 \%$ possuíam entre 25 e 30 anos; $56 \%$ entre 31 e 35 anos; e $33 \%$ com idade igual ou superior a 40 anos.

Referente à formação acadêmica, verificou-se que entre os respondentes $67 \%$ possuíam algum tipo de especialização na área da Educação; os 33\% restantes não tinham esse tipo de formação. Do total, $83 \%$ eram mestres e 17\% estavam se titulando, porém ninguém possuía ainda o título de doutor.

Depois de traçar o perfil do respondente foi o momento de refletir sobre as ações extensionistas, e, para isso foram elaboradas questões específicas para compreender o “olhar" dos coordenadores. Uma delas tratava do período de vigência. O resultado quantitativo demonstrou que o auge de sua implantação nesse campus foi entre 2009 e 2011 onde foram criados dois novos projetos por ano. Neste período, o plano de carreira da IES exigia que os docentes desenvolvessem extensão, trazendo, portanto, benefícios para a comunidade. Dos projetos analisados, 6 tiveram auxílio de acadêmicos e a média era de dois bolsistas cada.

Outra indagação aos respondentes foi sobre o conceito de extensão universitária. Foi factível que as respostas se complementaram, pois $46 \%$ informaram a categoria, relação 
com a sociedade e outros $46 \%$ sugeriram a socialização do conhecimento; além disso, $8 \%$ indicaram o tripé constitucional. Desta forma, destaca-se que para socializar o conhecimento produzido na universidade, é preciso que haja uma interlocução com a sociedade. Verificar detalhamento da conceituação na tabela 01 , onde se referenda que a extensão caracteriza uma das formas de atuação universitária, pois é uma maneira de devolver atividades na e para a comunidade.

Quando os respondentes foram questionados se conheciam a tríplice função universitária e se sabiam quais eram, todos responderam afirmativamente. Alguns fragmentos destacam essa concordância:

\footnotetext{
Ensino: oferta da graduação - concentra-se nas graduações, na apropriação dos conceitos e formação profissional (Entrevistado 03).

Pesquisa: solução de problemas - é a busca por solucionar um dado problema que venha a contribuir com o desenvolvimento da sociedade e que tragam contribuições ao estado da arte de uma determinada ciência (Entrevistado 01).

Pesquisa: é uma das principais formas de desenvolvimento da sociedade mundial (Entrevistado 05).

Extensão: socialização do conhecimento e atividades voltada para comunidade - é propiciar o conhecimento produzido dentro da universidade, fazendo com que ultrapasse os muros e chegue as pessoas que não possuem acesso a universidade (Entrevistado 01).
}

Com base nos dados coletados na definição do conceito e pelo reconhecimento da função constitucional, pode-se destacar que os coordenadores compreendem a extensão como uma forma de socializar o conhecimento produzido pela universidade e transmitido através de atividades acadêmicas direcionadas para a comunidade externa. Assim, somente será extensão se “[ [...] for voltada para o objetivo de tornar acessível à sociedade o conhecimento de domínio da universidade, seja por sua própria produção, seja pela sistematização ou pelo estudo do conhecimento universal disponível”. ${ }^{4}$

Segundo o respondente 08, a extensão "é uma forma de interagir com a sociedade, o ensino acompanha a extensão. Uma vez que você realiza extensão você está ensinando, transmitindo seus conhecimentos [...]”. Deste modo, os três elementos se completam, no momento que a extensão fornece o material para o desenvolvimento da pesquisa, e 
ao ensino o entendimento da realidade necessário no processo de ensino aprendizagem. ${ }^{3}$

Quando questionados se as universidades deveriam sair do seu espaço físico e buscar inserção na sociedade, todos os participantes responderam que sim. $\mathrm{O}$ entrevistado 05 justificou que "a universidade é formadora de opinião e para o desenvolvimento de toda uma sociedade necessita buscar as pessoas que não pertencem ao meio acadêmico, e unir forças para uma causa comum, o desenvolvimento e a qualidade de vida”.

Para outro coordenador, "a universidade deve estar presente na sociedade, pois faz parte dela. Deve atentar aos problemas sociais e buscar através de suas bases de conhecimento contribuir com a busca de soluções" (Entrevistado 06). Porém, um dos limites encontrados na análise dos dados foi que a extensão é divulgada superficialmente no ambiente acadêmico (50\% das respostas), apresentada apenas para um determinado público e deixando a desejar a divulgação das atividades (10\% dos indicativos de respostas).

Isso remete à reflexão de que a extensão universitária nesse campus não está fortalecida no ambiente acadêmico como deveria. É preciso que haja discussão e apresentação das atividades realizadas e, embora sejam ações externas à sala de aula são oportunidades ímpares de produção do conhecimento; portanto, de práticas pedagógicas articuladas à sociedade.

O entrevistado 01 complementa informando que, desse modo, é possível:

[...] propiciar a sociedade a oportunidade de estar presente na universidade, trazendo em alguns casos para dentro da universidade e em outro indo até a comunidade proporcionar o acesso ao conhecimento produzido dentro da universidade, propiciando assim um diálogo aberto entre universidade e um determinado público que acaba por favorecer a construção do conhecimento do cidadão como da universidade.

Também foi solicitado aos coordenadores se é possível a universidade, por meio dos projetos, socializar e potencializar o conhecimento produzido. Todas as respostas foram afirmativas. Este conhecimento é caracterizado pelo "aprender a fazer, aprender a aprender, aprender a conviver e aprender a ser" ${ }^{23}$, permitindo a troca de 
conhecimentos e o aprimoramento das ações já realizadas, assim como a implementação de novas experiências aos acadêmicos e aos envolvidos nessas atividades.

Para o respondente 03, através dessas atividades “[...] é possível externalizar o conhecimento científico e receber dos participantes o conhecimento empírico. A junção dessas fontes de informações determina um novo olhar para o objeto de pesquisa e gera novos conhecimentos". Assim, pode-se inferir um dos maiores desafios que é o enriquecimento da relação entre a universidade e a sociedade. $\mathrm{O}$ mesmo entrevistado esclarece que por meio dos projetos "a Universidade tem a oportunidade de estreitar os laços com sociedade e também captar quais são as demandas existentes em cada área do conhecimento. Com isso é possível um direcionamento para atividades que são de sua competência”.

Vale destacar que os projetos são um meio de divulgação da IES, pois através destes é possível “[...] despertar no cidadão o desejo de pertencer à universidade (entrevistado 01)". O respondente 08 expõe que "uma vez que você leva a universidade através da extensão até a sociedade ela passa a conhecê-la e pode desenvolver interesse de ingresso, assim proporcionando seu fortalecimento".

Para alcançar o objetivo estabelecido nesta investigação buscou-se através do "olhar" dos coordenadores verificar se nas atividades extensionistas realizadas ocorreram transformações na sociedade e no meio acadêmico. Todos os entrevistados responderam que sim e informaram que foram positivas. Para finalizar a coleta de dados deste estudo de caso, a última questão solicitava as limitações e desafios na execução diária da extensão nesta IES.

Com relação às limitações informadas pelos coordenadores são de várias naturezas, porém, a mais aclamada foi o limite de bolsas (26\%). O entrevistado 09 esclareceu que "um fator limitante é o número de acadêmicos disponíveis e com interesse em participar das ações”. A segunda maior indicação foi a infraestrutura (22\%) na época da criação dos projetos, levando em conta que o auge se deu entre 2009 e 2011. A dificuldade de ordem financeira (22\%) também foi sinalizada como limitação, seguida da burocracia institucional (15\%) e do tempo (10\%) entre outras categorias. 
Os respondentes também deveriam responder quais foram os desafios na execução dos projetos. Uma grande parte das assertivas citou apenas as limitações, e apenas $55 \%$ dos coordenadores informaram os desafios. Dentre as categorias, o maior desafio foi a ampliação do projeto (23\%), seguida pelo incentivo (11\%), como menciona o entrevistado 04 ao dizer que "o maior desafio encontrado foi de levar aos acadêmicos o gosto pela pesquisa”. A operacionalidade dos projetos também ocupou uma categoria com $11 \%$ das indicações.

Levando em consideração o levantamento teórico e os dados da pesquisa de campo, sustenta-se que, ao possibilitar a articulação entre universidade e sociedade, a extensão promove a troca de saberes sistematizados, garantindo o fortalecimento necessário entre a IES e os diversos setores da sociedade.

A partir da realização deste estudo e da análise dos projetos de extensão desenvolvidos na Unemat de Colider/MT, foi possível conhecer as atividades desenvolvidas por essa IES. Destaca-se, finalmente, que através dessas ações a universidade se fortalece, ao socializar com a sociedade o saber que produz e as informações que detém, permitindo a consolidação entre teoria e prática, além da formação de cidadãos conscientes de sua realidade local.

\section{Conclusão}

O foco desta investigação foi a extensão universitária e se constituiu numa tarefa árdua e complexa, pois era necessário entendê-la como um mecanismo de aproximação da universidade com a sociedade, um elo que possibilita integrar as atividades imputadas às IES na Constituição Federal.

Percebe-se que a extensão é uma das funções universitárias que, juntamente com o ensino e a pesquisa, possibilita que as universidades cumpram sua responsabilidade no que se refere à contribuição em relação ao desenvolvimento econômico e social da região que atende. $\mathrm{E}$, para que isto se torne possível, é preciso que socializem na comunidade os conhecimentos que produzem nas pesquisas, o que acontece por meio dos projetos extensionistas. 
A presente investigação permitiu compreender a partir do "olhar" dos coordenadores dos projetos de Extensão sua articulação com a sociedade. Primeiramente realizou-se uma pesquisa bibliográfica sobre o surgimento das universidades, enfatizando alguns acontecimentos marcantes, tais como a consolidação tardia no Brasil. Além disso, foi conceituada a extensão universitária que compõe o tripé institucional juntamente com o ensino e a pesquisa.

As transformações que ocorreram ao longo dos anos na Educação Superior foram necessárias para que, além de formar cidadãos críticos através da disseminação do conhecimento historicamente produzido, também pudesse estar comprometida com a inserção na comunidade. A investigação constatou que a socialização do conhecimento acontece através da extensão que é o elo articulador entre a universidade e a sociedade.

O levantamento bibliográfico subsidiou a pesquisa de campo onde foi elaborado um questionário destinado aos coordenadores dos projetos de Extensão, permitindo analisar a relevância das ações extensionistas desenvolvidas pela Unemat, no Campus de Colider/MT. No decorrer deste estudo, verificaram-se vários fatores relevantes, entre eles, o auge da criação dos projetos entre 2009 e 2011.

Pode-se afirmar que, através desses projetos, a Unemat potencializa suas ações junto a sociedade, gerando, deste modo, novos conhecimentos, contribuindo, para a formação cidadã. Com base na análise dos dados da pesquisa de campo, averiguou-se que os coordenadores dos projetos que respondem ao questionário identificam a importância da extensão e a reconhecem como função da universidade.

Resultante de uma troca de saberes ocorrida entre as partes, segundo a percepção dos respondentes, a universidade se fortalece promovendo o intercâmbio de valores culturais e científicos, sendo que os projetos extensionistas cumprem a função de divulgação do conhecimento produzido.

Porém, no que se refere à informação das atividades na comunidade acadêmica, foi notório que não vem sendo divulgada e discutida como deveria, já que de acordo com os coordenadores é superficialmente valorizada. Observa-se assim que as ações da extensão dentro do espaço acadêmico não recebem a merecida atenção, mesmo sendo 
um forte componente na constituição de indivíduos críticos-reflexivos e participativos, como complemento necessário para formação acadêmica inicial.

Considera-se, então, que há necessidade de ampla divulgação dos projetos para a comunidade acadêmica. Para que possam despertar a curiosidade, o interesse e a participação dos acadêmicos, não apenas como bolsistas, mas, como colaboradores e/ou voluntários ativos no processo.

É imprescindível destacar, por fim, que a universidade que desempenha o tripé constitucional (ensino, pesquisa e extensão) consegue assimilar as demandas sociais e incorporá-las em suas ações cotidianas, o que fortalece as IES que têm como foco o atendimento da sociedade em geral.

\section{Referências}

1. ROSSATO, R. Universidade: nove séculos de historia. Passo Fundo: Ediupf, 1998.

2. COSTA, M. P.; AlmeidA, M. O. D. B.; FREITAS, T. S. Ensino, pesquisa e extensão: compromisso social das universidades. Disponível em: $<$ http://www.uftm.edu.br/upload/ensino/tcc_teresinha.pdf $>$. Acesso em: o9 jan. 2013.

3. BRASIL. Constituição da República Federativa do Brasil. Brasília: Câmara dos Deputados, Coordenação de Publicações, 2008.

4. BOTOMÉ, S. P. Pesquisa alienada e ensino alienante: o equívoco da extensão universitária. Petrópolis: Vozes, 1996.

5. SANTOS, M. P. Extensão universitária: espaço de aprendizagem profissional e suas relações com o ensino e a pesquisa na educação superior. Conexão UEPG, Ponta Grossa, v. 8, n. 2, 2012. p. 154-163.

6. NEZ, E. Em busca da consolidação da pesquisa e da pós-graduação numa universidade estadual: a construção de redes de pesquisa. Tese de Doutorado em Educação da Universidade Federal do Rio Grande do Sul (UFRGS), Porto Alegre, 2014.

7. RAMPAZZO, L. Gestão universitária: quando e como nasceram as universidades? Disponível em: 
<http://fabiogarciareis.com/blog/media/blogs/a/artigos_de_terceiros/Nascimentod asuniversidadesLino.pdf $>$. Acesso em: 18 fev. 2013.

8. ZAINKO, M. A. S. Planejamento, universidade e modernidade. Curitiba: AllGraf, 1998.

9. BUARQUE, C. A refundação da universidade. Brasília: Senado Federal, 2004.

10. TEIXEIRA, A. Ensino superior no Brasil: análise e interpretação de sua evolução até 1969. Rio de Janeiro: Fundação Getúlio Vargas, 1989. Disponível em: <http://www.bvanisioteixeira.ufba.br/livros/chama_cap9.htm>. Acesso em: 19 fev. 2013.

11. MARtins, C. B. O ensino superior brasileiro nos anos 90. São Paulo em perspectiva. v. 14 n. 1 São Paulo: jan./mar. 2000. Disponível em: <http://www.scielo.br/pdf/spp/v14n1/9801.pdf>. Acesso em: 27 fev. 2013.

12. CERVO, A. L., BERViAn, P. A. Metodologia científica. 3. ed. São Paulo: Mc Grow-Hill do Brasil, 2002.

13. MARCONI, M. A.; LAKATOS, E. M. Fundamentos de metodologia científica. 6. ed. São Paulo: Atlas, 2005.

14. SANTOS, V.; CANDELORO, R. J. Trabalhos acadêmicos: uma orientação para a pesquisa e normas técnicas. Porto Alegre: 2006. Disponível em: $<$ http://books.google.com.br/books?id=REvrU90M2OUC\&pg=PA 156\&dq=Trabalh os+Acad\%C3\%AAmicos:+Uma+orienta $\%$ C3\%A7\%C3\%A3o+para+a+pesquisa+e +nor mas $+\mathrm{t} \% \mathrm{C} 3 \%$ A9cnicas $\& \mathrm{hl}=\mathrm{pt}-$

PT\&sa $=$ X\&ei $=1$ nIRUbq4PIXZsgb_8oCIBw\&ved $=0$ CDwQ6AEwAA $>$. Acesso em: 29 jan. 2013.

15. NEVES, J. L. Pesquisa qualitativa: características, uso e possibilidades. 1996. Disponível em: < http://www.ead.fea.usp.br/cad-pesq/arquivos/c03-arto6.pdf>. Acesso em: 01 fev. 2013.

16. ANDRE, M. E. D. A. Estudo de caso: seu potencial na educação. Cadernos de pesquisa. N. 49. maio 1984 , p. 51-54.

17. GIL, A. C. Estudo de caso. São Paulo: Atlas, 2009. 
18. IBGE. Instituto Brasileiro de Geografia e Estatística. Área territorial oficial. Disponível em: <http://www.ibge.gov.br/home/geociencias/areaterritorial/principal.shtm>. Acesso em: 18 set. 2013.

19. MATO GROSSO. Secretaria do Estado de Meio Ambiente. Mapas dos biomas. Disponível

em: $<$ http://www.sema.mt.gov.br/index.php?option=com_content\&view $=$ article\&id $=170$ \&Itemid=>. Acesso em: 18 set. 2013.

20. UNEMAT. Universidade do Estado de Mato Grosso. Campus Universitário Vale do Teles Pires. Disponível em: <http://www.colider.unemat.br/site/?link=news\&idnew=223>. Acesso em: 29 jan. 2013.

21. HISTÓRICO. Disponível em: $<$ http://www.unemat.br/index/conteudo.php?id_conteudo $=1$ http://www.unemat.br/ index/conteudo.php?id_conteudo=1>. Acesso em: 18 set. 2013.

22. STOLARCZKI, F. E. Extensão universitária: limites e desafios. Monografia do Curso de Licenciatura em Computação, na Universidade do Estado de Mato Grosso (UNEMAT), Colider, 2013.

23. DELORS, J. et all. Educação um tesouro a descobrir. Relatório para a UNESCO da Comissão Internacional sobre Educação para o século XXI. UNESCO. 1998.

\section{Anexos}

Quadro 01. Relação dos projetos de extensão - Unemat Campus Colider.

\begin{tabular}{|l|l|}
\hline \multicolumn{1}{|c|}{ PROJETOS ENCERRADOS } & PROJETOS EM DESENVOLVIMENTO \\
\hline $\begin{array}{l}\text { A inclusão digital formando } \\
\text { cidadãos do século XXI }\end{array}$ & Campus On-line \\
\hline $\begin{array}{l}\text { Formação continuada dos egressos } \\
\text { e licenciados do Departamento de } \\
\text { Computação do Campus }\end{array}$ & CienciAtividade \\
$\begin{array}{l}\text { Universitário Vale do Teles Pires - } \\
\text { Colider MT }\end{array}$ & \\
\hline $\begin{array}{l}\text { O estudo e sistematização de } \\
\text { plataformas livres no auxílio a } \\
\text { formação continuada de professores } \\
\text { através do - ensino a distância }\end{array}$ & Promes: projeto de metareciclagem na sociedade \\
\hline
\end{tabular}


PROACI: Projeto de Administração Robótica Educacional

e Filtro de Conteúdo na Internet

Tele Centros

Unitrabalho: Incubação

de Empreendimentos Econômicos Solidários e

Sustentáveis da Comunidade Santa Inês e na

região do Vale dos Teles Pires - Território

Portal da Amazônia

Fonte: Stolarczki. ${ }^{23}$

Tabela 01. Conceito de extensão universitária.

\begin{tabular}{l|c}
\hline INDICATIVOS DE RESPOSTAS & PORCENTAGEM (\%) \\
\hline Relação com a sociedade & 46 \\
\hline Socialização do conhecimento & 46 \\
\hline Tripé constitucional & 8 \\
\hline TOTAL & $\mathbf{1 0 0}$ \\
\hline
\end{tabular}

Fonte: Stolarczki. ${ }^{23}$ 